\title{
Case study of "Meilong model" ecological animal husbandry shareholding cooperatives in Qinghai
}

\author{
Hubin Yin · Yaqi Gao · Wenyuan Liu · Cairang Dongzhu • Wei Jiang
}

Received: 7 April 2019 / Accepted: 29 October 2019 / Published online: 27 November 2019 (C) The Author(s). 2019 Open Access This article is distributed under the terms of the Creative Commons Attribution 4.0 International License (http://creativecommons.org/licenses/by/4.0/), which permits unrestricted use, distribution, and reproduction in any medium, provided you give appropriate credit to the original author(s) and the source, provide a link to the Creative Commons license, and indicate if changes were made.

\begin{abstract}
This article examines Meilong animal husbandry cooperatives in the Haixi Prefecture of Qinghai Province, China as a study case, using information gathered through field surveys and questionnaires to explore the systemic structure and operational mechanisms of Meilong Cooperatives, as well as its impacts on pastoral areas and herdsmen. Based on the results, the main contribution of the Meilong Model is providing a new way for pastoral villages to pursue development through joint-stock cooperatives, and thus represents the long-term direction of pastoral area development. This model reforms the traditional cooperative concept that naturally arises among herdsmen; Meilong Share-holding Cooperative guarantees the equal rights of small or poor households to participate in the management of cooperatives on the basis of "one household, one vote", rather than the principle of "shareholders have the right to manage, vote and speak according to the proportion of shareholding" found in the joint-stock systems of
\end{abstract}

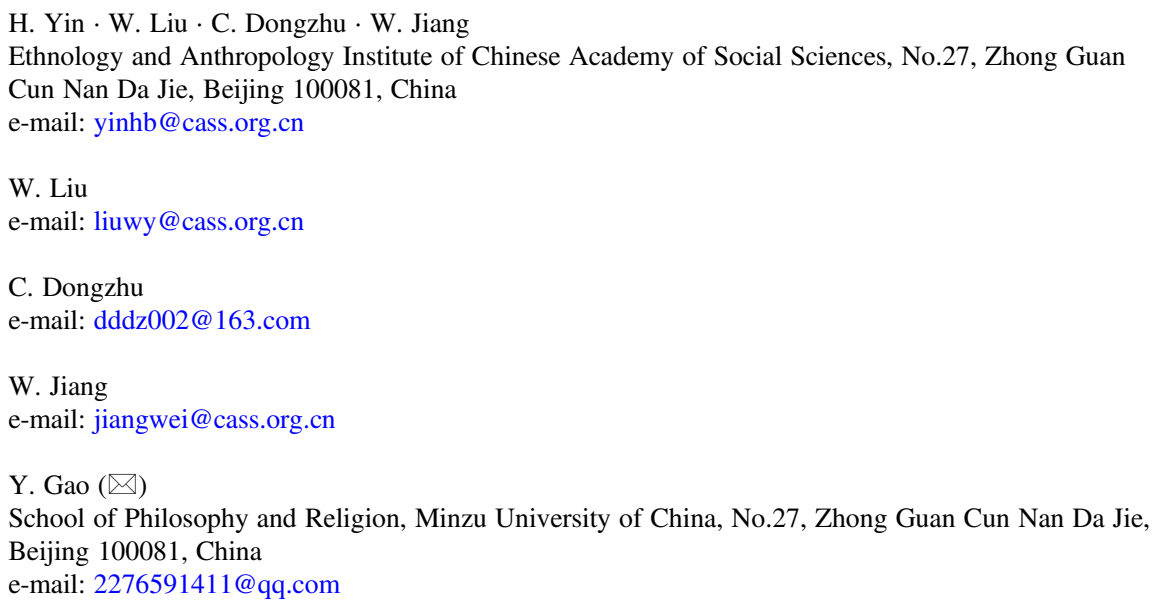


modern enterprises. It localizes the shareholding system theory to be more acceptable and feasible in order to ensure the survival of animal husbandry cooperatives.

Keywords Meilong model $\cdot$ Joint-stock cooperative $\cdot$ Ecological animal husbandry $\cdot$ Sustainable development

\section{Background}

In the past 40 years of reform and opening up, especially since the Eighteenth National Congress of the Communist Party of China, Tianjun County in Qinghai Province, in accordance with the overall requirements the provincial Party Committee and the provincial government, established the general requirements of "the protection of the grassland ecological environment as the premise, the scientific and rational utilization of grassland resources as the basis, the promotion of grassland and livestock balance as the core, the transformation of modes of production and management as the key, and the harmony between man and nature as the goal'" With this support and guidance, the pilot project of joint-stock cooperative management was carried out in the village of Meilong, implementing the concept of ecological animal husbandry development in "the zoning and rotation of grazing, rational levels of livestock, and the integration of resources and scale management"; constructing ecological animal husbandry with large-scale, intensive management as the primary part; exploring and summarizing the "joint-stock cooperative management model", also known as "Meilong model", or "grassland contracting". The mode of operation for joint-stock cooperative operation accounts for management rights, stock discounts, the specialized division of the labor force, the quantification of a production index, remuneration for labor according to work, and dividends according to share (Yu 2011).

The Meilong Ecological Animal Husbandry Cooperative, as a successful model of "turning the poorest and backward village in the county into a well-known, rich, civilized village, and breaking out an environmentally friendly way that enriches the people appropriately through the sustainable development of pastoral mechanism system", has been recognized by the Ministry of Agriculture of China and identified as a leader in the construction and development of ecological animal husbandry in Qinghai Province. The Meilong Cooperative has been awarded the honorary titles of "provincial demonstration cooperative", "national demonstration cooperative" and "state-level advanced collective".

The existing study focused on the governance structure of "Meilong Model" and its outputs. Xiaohua Min (2018) made an analysis on the relationships among Husbandry Cooperative, consumers, governments and the environment of "Meilong Model". Min Zhang (2018) introduced the detail measures of "Meilong Model" and the corresponding results. Shuangyuan Li (2011) took Meilong Model as a key case, discussing about the long-term mechanism for Ecological Animal Husbandry in Qinghai province. Weihua Liang (2016) made an investigation on three herdsman professional cooperatives in Xinyuan Town, analyzing the establishment, operating conditions and existing problems of cooperatives. He put 
forward the countermeasures and suggestions to promote the steady development of the professional cooperatives of herdsmen. These research paid few attention to the internal governance and the multi-level motives of Ecological Animal Husbandry Shareholding Cooperatives, nor the universality of Meilong Model. However, these questions would be critical important for the sustainability and effectiveness of Ecological Animal Husbandry Shareholding Cooperatives. Can the "Meilong Model" be used universally? Great theoretical value and practical significance can be attained by studying the developmental path of the Meilong Ecological Animal Husbandry Cooperative since its establishment in 2008, in order to analyze its organizational structure and operational mechanism and to test the perfection of its internal organization, systemic design and supervision system. Such a study will deepen the understanding and application of the stock cooperative system of ecological animal husbandry, and its objective evaluation for lessons will promote the sustainable development of other pastoral areas.

With this aim, the authors of the present study went to the Haixi Prefecture of Qinghai Province in order to complete group interviews in 15 governmental departments, detailed interviews with more than 30 cadres, individual interviews with herdsmen, 50 questionnaires, and 39 household questionnaires. By having in-depth conversation with the herdsmen, the authors obtained detailed first-hand information. Through these in-depth interviews, questionnaires and analysis, this paper studies the organizational structure and operational mechanisms of the Meilong model and provides a reference for the development of other pastoral areas. The data in the report were obtained from the Statistics, Finance, Environmental Protection, Animal Husbandry and Forestry Bureaus of Tianjun Country as well as from the Meilong Cooperative, questionnaires, and interviews.

\section{The formation and development of "Meilong model" ecological animal hus- bandry shareholding cooperatives}

Prior to 2008, Meilong was a poor, underdeveloped village in Tianjun County. The villagers had few livestock. Besides their own livestock, the main livelihood of Meilong was renting their grasslands to others. However, the low rental price (2-5 yuan per mu) was insufficient to maintain their livelihoods; the tenants often overgrazed and were reluctant to protect the grasslands because they were not the owners, resulting in serious damage to the grasslands; finally, because the grasslands belong to different grazing units, clearing the boundaries of their grasslands and set fences raised issues about the damage done to the livestock and pasture rotation. As a result, Meilong Village was in poverty because of its low income, while also having an imbalance of grassland and livestock that led to the degradation of grassland ecology.

In this context, the villagers gradually increased their own cattle and sheep. In 2008, they consolidated their livestock and grassland in the form of a joint-stock system with the cooperatives for unified management, alleviating the degradation of grassland caused by the imbalance between grassland and livestock. In July 2008 , according to the principles of voluntary shareholders, free withdrawal and 
democratic management, the Meilong Ecological Animal Husbandry Cooperatives in Tianjun County were established by leading herdsmen to share pastures and livestock. ${ }^{1}$

Through the cooperative transformation of ecological animal husbandry achieved by the joint-stock venture, Meilong leapt from the poorest and backward village in the county to a wealthy village, winning the honorary title of "National Demonstration Cooperative". At present, there are 214 herdsmen in 72 households, with a $100 \%$ participation rate; $132,400 \mathrm{mu}$ of land, including $110,300 \mathrm{mu}$ of grassland, with a 100\% participation rate; 13,605 livestock of all kinds, with a100\% participation rate; the herdsmen share in grassland and livestock, with a value of 2400 yuan per share. Based on the principles for balancing pasture and livestock, 9869 livestock were kept in stock in 2017, including 9178 Tibetan sheep and 691 yaks. In 2017, there were 5589 livestock, including 5267 Tibetan sheep and 322 yaks, with a total income of 3.88 million yuan. ${ }^{2}$

\section{Reform of the share-holding cooperative system and its application in the Meilong model}

The applicability of a shareholding system to ecological animal husbandry in Meilong Village

Shareholding systems raise capital by issuing stocks in accordance with certain legal procedures, create legislative enterprises, and implement social possession and the common use of the factors of production. Such an enterprise has an independent legal status and is an independent economic entity that is responsible for its own profits and losses. Shareholding systems are both a form of capital organization of modern enterprises, and also a property right system. ${ }^{3}$ The shareholding system, also known as a "stock economy", refers to an economic organization form that centralizes the decentralized factors of production belonging to different people through the means of issuing shares, uses these resources uniformly, operates on a rational basis, assumes its own profits and losses, and pays dividends according to those shares. Its basic feature is the separation of ownership and right to use of factors of production. With the premise of not changing ownership, the decentralized right to use is transformed into the centralized right to use. It is helpful to rapidly unite the dispersed productive forces with different levels into concentrated, high-level and intensive social productive forces.

\footnotetext{
${ }^{1}$ This information is from the report of Qinghai Animal Husbandry Department "Experiences in the Development of Ecological Animal Husbandry in Qinghai Province" from "Symposium on the Docking of Baixian Investigation Program" of the Propaganda Department of the Provincial Party Committee, June 5, 2018.

${ }^{2}$ The information comes from the oral statements of Jun Qing, the chairman of Meilong Cooperative, and other five herdsmen.

${ }^{3}$ According to the fieldwork study and archives of the research team in Meilong Cooperative since its establishment, as well as the in-depth visits to Chairman Jun Qing and Accountant Sang Jie.
} 
Enterprises with legal persons shall have social possession and joint use of production. The enterprise has independent legal person property and is an independent economic entity operating independently and responsible for its own profits and losses. Share-holding system is not only a form of capital organization of modern enterprises, but also a property right system. Share-holding system, also known as "stock economy", refers to an economic organization form that centralizes decentralized factors of production belonging to different people by way of share-holding, uses them uniformly, operates rationally, assumes its own profits and losses, and dividends according to share. Its basic feature is the separation of ownership and right to use of factors of production. On the premise of not changing ownership, a formerly individual right to use is transformed into a centralized right to use. Such a step rapidly unites the dispersed productive forces into concentrated, high-level, intensive social productive forces.

Share-holding cooperatives combine share-holding systems and cooperative systems. Share-holding systems emphasizing capital cooperation in allowing investors to participate in the management and profit distribution according to the amount of their shares while assuming limited economic responsibilities; a cooperative system is a voluntary association in order to meet common economic, social and cultural needs, which implements the democratic self-management, mutual assistance and cooperation along with the principle of "one person, one vote", which, when based on the distribution of members according to their work, functions an economic organization system (Fu 2006; Liu 2012). The share-holding cooperative system is a type of comprehensive economic organization that applies the primary modes of operation from the share-holding system while maintaining the unique characteristics of the collectivist "cooperative system" found in China. In particular, the share-holding cooperative system differs from the share-holding system of modern enterprises in that other systems give the right of management, voting and discourse according to the proportion of shares that an individual owns, while the share-holding cooperative guarantees one vote per household, as pictured in Fig. 1. This arrangement guarantees the equal rights of small or poor households to participate in the management of cooperatives, and encourages their enthusiasm in the prospect.

The core mechanism of the share-holding system reform is that decentralized production factors are centralized through issuing shares, thus separating the rights of ownership from the right of management to make more effective use of the factors of production. The typical rural share-holding cooperative system in China will be an enterprise-type joint-stock cooperative system, a community-type joint-stock cooperative system, or a land joint-stock cooperative system. The Meilong Ecological Animal Husbandry cooperative effectively combines the latter two. When it was established, due to the dispersal of the factors of production in Meilong village, a single family could not effectively utilize their resources, and the productivity was low. With the introduction of a share-holding system, it was in the best interest of the herdsmen to keep the contracted management right of grassland and the ownership of livestock unchanged, to create shares from their livestock, grassland and other factors of production, to integrate these factors of production, and to execute an intensive, largescale management. This transition also helps to avoid the degradation of grassland caused by its rental to outsiders for grazing. This share-holding cooperative will be similar in practice to land share-holding cooperatives where farmers legally own the 


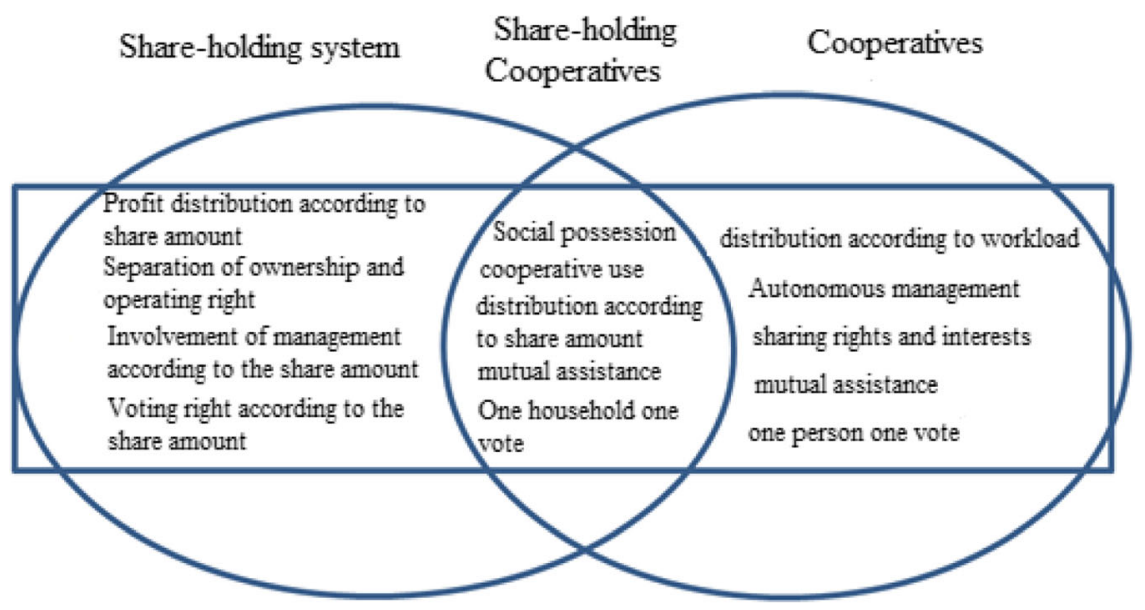

Fig. 1 Distinction of share-holding cooperatives with share-holding systems and cooperatives. Source: made by authors

right to contractual management of land which they can convert into shares according to land use and income, as compared to livestock stock cooperatives which legally own the grasslands and convert those into shares according to their different qualities while also converting cattle and livestock into shares; concurrently, the shareholding system principle of " management and voting rights according to the proportion of ownership " will be transformed into the principle of "one household, one vote". In view of the traditional economic and cultural customs in pastoral societies, this reform consolidates the necessities of development into a matter of mutual assistance and cooperation, while eliminating the psychological demands of herdsmen related the ownership of their cattle and sheep in the pasture. Therefore, the creation of the share-holding cooperative system aids Meilong village to escape its predicament related to economic development, while also conforming to the psychological characteristics of herdsmen, which corresponds to the objectives for pastoral development.

Reform practices in the development of Meilong ecological animal husbandry share-holding cooperatives

In July 2008, based on the principles of voluntary shareholders, free withdrawal, and democratic management, Meilong Village established the Meilong Ecological Animal Husbandry Cooperative, guiding herdsmen to become shareholders based on their grassland and livestock. The transformation into this stock cooperative system aided the development of Meilong Village's ecological animal husbandry. The specific reform mechanism that was utilized can be summarized formation, management, marketing and distribution (see Table 1). ${ }^{4}$

\footnotetext{
${ }^{4}$ The information comes from the oral statements of Jun Qing, the chairman of Meilong Cooperative, and other five herdsmen.
} 
Table 1 Meilong Cooperative Income Distributions Data (2008-2017)

\begin{tabular}{|c|c|c|c|c|c|c|c|c|c|}
\hline Year & $\begin{array}{l}\text { Total } \\
\text { income } \\
(10,000 \\
\text { Yuan) }\end{array}$ & $\begin{array}{l}\text { Net } \\
\text { income } \\
\text { (10,000 } \\
\text { Yuan) }\end{array}$ & $\begin{array}{l}\text { Income per } \\
\text { head (Yuan) }\end{array}$ & $\begin{array}{l}\text { Dividend } \\
\text { income } \\
\text { (10,000Yuan) }\end{array}$ & $\begin{array}{l}\text { Total } \\
\text { share }\end{array}$ & $\begin{array}{l}\text { Poor } \\
\text { household } \\
\text { share }\end{array}$ & $\begin{array}{l}\text { Project } \\
\text { share }\end{array}$ & $\begin{array}{l}\text { Actual } \\
\text { share }\end{array}$ & $\begin{array}{l}\text { Dividend } \\
\text { per share }\end{array}$ \\
\hline 2008 & & & 4800 & & & & & & \\
\hline 2009 & 134.50 & 122.65 & 7658 & 23.25 & 1183.54 & & & & 196.51 \\
\hline 2010 & 247.72 & 152.75 & 9729 & 30.00 & 1172.05 & & & & 255.96 \\
\hline 2011 & 283.27 & 219.80 & 14,000 & 80.00 & 1382.64 & & & & 578.60 \\
\hline 2012 & 524.91 & 339.20 & 16,000 & 126.00 & 3308.63 & 8.37 & & 3300.27 & 381.79 \\
\hline 2013 & 604.29 & 400.68 & 18,900 & 150.00 & 3406.94 & 8.71 & & 3398.23 & 441.41 \\
\hline 2014 & 485.90 & 407.35 & 19,215 & 156.00 & 3471.77 & 11.25 & & 3460.52 & 450.80 \\
\hline 2015 & 347.09 & 335.72 & 15,400 & 122.29 & 4084.31 & 7.76 & & 4076.55 & 300.00 \\
\hline 2016 & 848.51 & 411.53 & 17,569 & 138.18 & 4195.96 & 8.45 & & 4187.51 & 330.00 \\
\hline 2017 & 540.40 & 540.40 & 20,865 & 150.00 & 4292.50 & $\begin{array}{l}\text { be out of } \\
\text { poverty }\end{array}$ & 1843.69 & 4287.07 & 349.89 \\
\hline
\end{tabular}

Source: Calculation of Income in the Meilong Ecological Animal Husbandry Cooperative from 2008 to 2017, Source: provided by Meilong Cooperative and the annual dividend table

\section{Formation of the cooperative: converting the means of productions into shares}

Households become shareholders through converting their grassland and livestock at 2400 yuan per share. The grassland shares were calculated according to the discount rate per mu in the contractual rights for the use of grassland, which is 2 yuan per mu in summer, 3 yuan per mu in autumn and 5 yuan per $\mathrm{mu}$ in winter. The actual procedure for converting the means of production into shares is described in Fig. 2:

\section{Management of the cooperative: a refined system with democratic management}

In changing from traditional animal husbandry production and operations to resource-intensive shareholding, production specialization, employment planning and marketing marketization, cooperatives realized that the internal management system that had existed from the beginning was not detailed enough, such that the ability of the cooperative to operate was not strong enough to meet the actual needs of development. Therefore, the internal operating system of cooperatives was revised and re-established. The revised operations included the eight systems of the asset allotment system, the self-feeding sheep allocation system, the outpatient fund advanced payment system, the livestock checking and counting system, the departing member study and inspection system, the cooperative managers salary standard, the qualitative and quantitative poverty alleviation system, and the three-industry development plan. In addition, in accordance with the articles of a cooperative association, the system of "four discussions and two publicities" on major matters must be followed, the file cards regarding membership should be established, the methods of improving dividend distribution should be improved, and the 


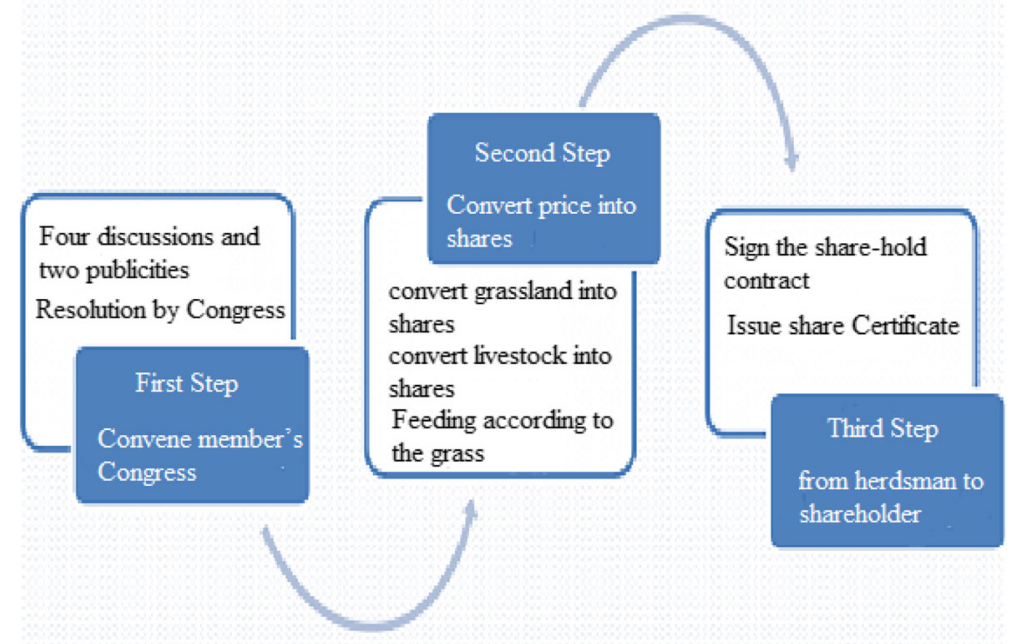

Fig. 2 The Conversion of the Means of Production into Shares. Source: Personal interviews and minutes of the cooperative

standardization of operations must be promoted. Although dividend paid out is calculated according to the number of shares, the voting rights of members are strictly implemented as "one household, one vote".

Marketing the cooperative: six unified actions to enable intensive operations on a large scale

Cooperatives depart from traditional decentralized farming method to instead implement the "six points of unity" model of management that uses "unified rotational grazing, unified fattening, unified epidemic prevention, unified mating, unified processing, unified marketing, and clustered farming" for livestock, in order to promote the large-scale, intensive production and operations in the cooperatives.

Distribution in the cooperative: payment according to labor, profits according to shares

After establishing the cooperative, the old pattern of distribution according to work has been changed, and a new method of distribution based on grassland ownership, livestock ownership, labor, skills, management and other factors was implemented, combining share dividends, wages, and performance rewards. After covering the office costs, the production costs, the salaries for herdsmen and management, the annual income of the cooperative shall not be less than $70 \%$ of the profit paid as 
the dividend to the members, and the surplus profits shall be used as a reserve fund to expand reproduction and performance appraisal. ${ }^{5}$

In addition, cooperatives also increase the shares of poor households in a rotation to promote focused poverty alleviation. Prior to 2008, Meilong Village was one of the poorest villages in among the sixty-two animal husbandry villages in the county. After the establishment of ecological animal husbandry shareholding cooperatives, a qualitative and quantitative poverty alleviation system was established to solve the problem of poor households that returned to poverty due to poor management. Since 2009, the cooperatives integrated the funds from the national project of "promoting poverty alleviation and development through the whole village". Every year, four poor households are alleviated by being given 225 sheep, which are managed by the cooperative. The cooperative distributes the production of ewes and lambs to the poor households, increase the shares and dividend benefits received by the poor households, rearrange the four poor households in the second year, and encourage them to join the members' shares. These measures promote the equalization of shares, narrowing the gap between the rich and the poor. ${ }^{6}$

To sum up, the establishment of cooperatives has integrated the scattered resources found in the hands of herdsmen. This engages the impact of moving to a larger scale, and allows for a concentration on improving infrastructure. By integrating and dividing the stocks of livestock and grassland, cooperatives broke through the traditional decentralized farming methods, and instead rationally allocated grassland resources, optimized the livestock structure, determined the appropriate number of livestock based on the available grassland, and promoted proper grazing, animal balance, and grassland protection. At the same time, the scientific utilization of grassland resources has increased, and the living standards and income level of herdsmen has also been raised.

The economic, societal and ecological effect of the Meilong model

After implementing the "six points of unity" management paradigm, the Meilong Cooperative has fully developed its scale economy in 10 years, achieving the goal of "a double increase, a double decrease, one optimization and four transformation" of production, management, organization and development, and thus achieved comprehensive ecological, economic and social benefits.

Before the establishment of the cooperative, Meilong herdsmen raised Tibetan sheep for 3 to 4 years, which consumed nearly $1500 \mathrm{~kg}$ of fresh grass a year while gaining no more than $2 \mathrm{~kg}$. Now, lambs raised by the cooperative can be released in 6-8 months, which not only saves on the grazing land, but also ensures the best quality of mutton for maximum economic benefit.

\footnotetext{
${ }^{5}$ Meilong Cooperative income statement 2008-2017, provided by Meilong cooperative social accounting office.

${ }^{6}$ The dividend distribution of poor households in Meilong cooperative is provided by Meilong cooperative social account.
} 
According to estimates, the grass yield per mu of the cooperative grassland has increased by $15-20 \mathrm{~kg}$, the vegetation coverage has increased by $10 \%$, which will entail certain ecological benefits. The grassland monitoring data from the County Environmental Protection Bureau show that the grassland in Tianjun County has recovered as well. The total grass yield increased from $2998 \mathrm{~kg}$ per hectare in 2011 to $4410 \mathrm{~kg}$ in 2017 ; meanwhile, the edible grass yield increased from $2895 \mathrm{~kg}$ per hectare to $3971 \mathrm{~kg}$ as the average grass height increased from $79 \mathrm{~mm}$ in 2011 to $97 \mathrm{~mm}$ in 2017, as shown in Fig. 3.

Considering the prior situation of Meilong, the ecological improvement is also remarkable. After the establishment of the cooperative in 2008, 28,800 mu of rotational grassland was established, and the balance of grass and livestock was executed. Five thousand eight hundred eighty-one livestock were reduced in a reasonable manner from the village, in order that the grassland could be restored to a better condition. Based on the calculations of the Bureau of Animal Husbandry and Forestry, the quantity of edible forage in Meilong Village increased by more than $10 \%$, the grass yield increased by $22.5 \%$, the fresh grass increased by $15-20$ $\mathrm{kg}$ per mu, and the vegetation coverage increased by $5-10 \%$, which has improved the ability of the village to continue in sustainable development.

Since 2012, the ratio of dam in the total livestock in Meilong has been controlled at more than $80 \%$, which is an increase of at least 35 percentage points compared with the previous ratio of $45 \%$. The survival rate of young livestock is over $80 \%$, the survival rate overall has climbed over $90 \%$, and the quality of

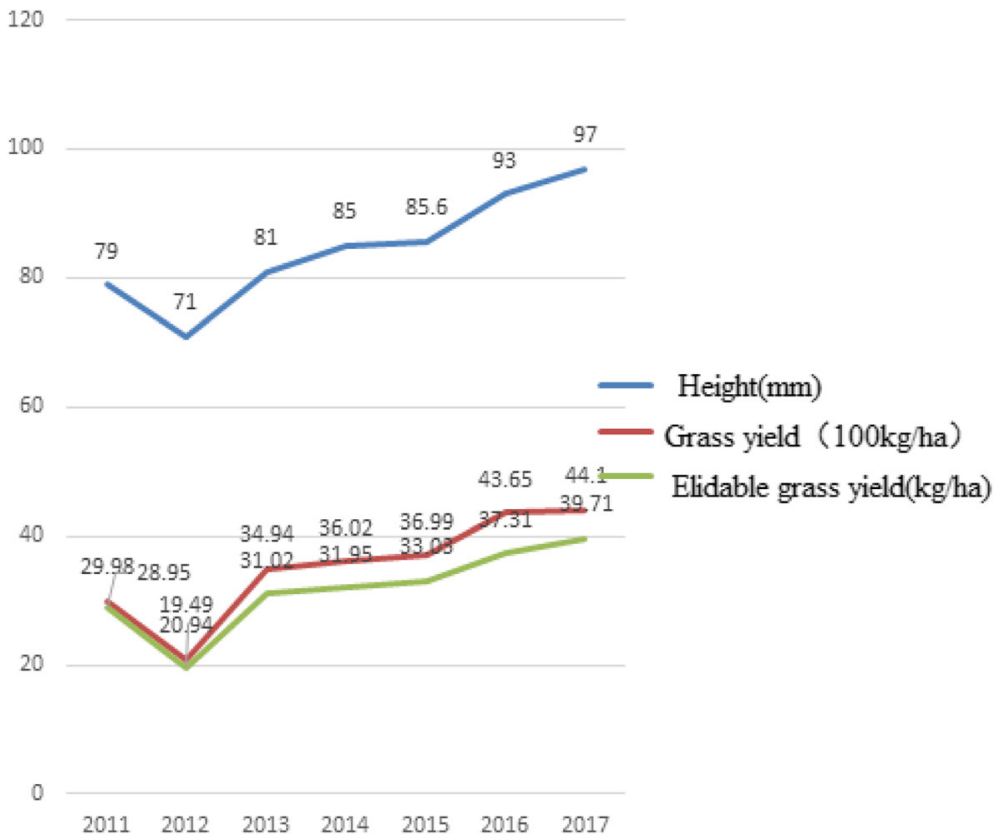

Fig. 3 Grassland recovery conditions in Tianjun (2011-2017). Source: Tianjun County Environmental Protection Bureau 
livestock has improved significantly. The "six points of unity" management paradigm has effectively promoted the construction of organic ecological pasture usage. On the basis of securing a unified certification of organic Tibetan sheep and yak livestock throughout the county, the Meilong Cooperative completed the work of installing electronic ear tags for livestock tracking and information gathering, grouping the livestock according to their grades, constructing an organic animal husbandry production system in an accelerated manner, and promoting a brand.

The operations of share-holding cooperatives increases the income of members, liberates the productive forces, broadens the channels for increasing the income of the herdsmen, and brings social benefits to herdsmen in 2017, the average income of members of the cooperative was 20,865 yuan, which had increased by 16,065 yuan compared to the average income of 4800 yuan at the beginning of the establishment, which reflects a growth rate of 334\%. Further, industry in the cooperative moved from a singular focus on animal husbandry to embracing secondary and tertiary industries. The surplus labor force in pastoral areas has been transferred from the work grassland animal husbandry, and the young, strong labor force is engaged in other non-pastoral industries; those who are older and working in the pastures can go to the city for the aged, and all school-age children are enrolled in school. At present, 42 herdsmen have settled in the county town; because all the cattle and sheep in the pasture been integrated in the cooperative in the form of shares, the original grassland boundary disputes have been eliminated, and the neighborhood is harmonious.. Afterwards, pensions and medical insurance will be paid for the members of the community, which will help the herdsmen feel more secure in their lives.

Whether considering the change in the net income of cooperatives or the per capita income of herdsmen from 2008 to 2017, Meilong Cooperative has achieved significant progress. As shown in Fig. 4, the per capita income, the dividend income, and the increase of net income in the cooperative show a consistent correlation, which indicates that the development of and distribution system in the cooperative improves the economic interests of herdsmen.

\section{Sustainable development in the Meilong model: striving for perfection with the idea reserve, organizational institutions, institutional design and supervising mechanisms}

The "Meilong Model" has been recognized as a successful model for the sustainable development of pastoral economies and operation. This model achieved the ecological, social and economic objectives of "reducing livestock and population without reducing income" and has become the object of study and imitation in Qinghai Province and even in other pastoral areas throughout China. ${ }^{7}$ The Meilong Cooperative has experienced 10 years of development from 2008 to 2018. It created a development model that includes the design of its internal organization

\footnotetext{
${ }^{7}$ See Qinghai Commissioner's Office: Village-based Task Force Leads Poor Village Cadres to Learn "Meilong Model".
} 


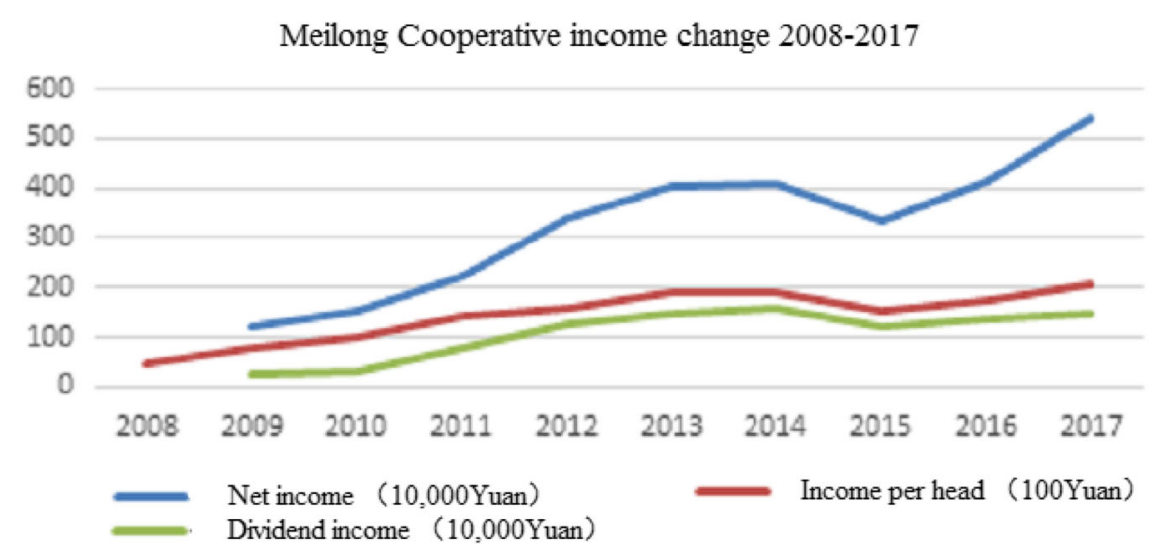

Fig. 4 Income in the Meilong Cooperative (2008-2017). Note: In 2015 and 2016, due to the depressed price of beef and mutton market, income declined slightly. Source: According to the income report statistics provided by Meilong Cooperative Social Account

and supervision mechanisms. Discussing the conditions for sustainable development and the theoretical and practical significance will help with testing the universality of the development model for other regions.

Based on the survey, the theoretical model and expected comprehensive effect of Meilong Stock cooperatives is revealed in Fig. 5. Through both questionnaires and interviews with local cadres and herdsmen, the research team found that the establishment of ecological animal husbandry share-holding cooperatives contributes to sustainable development. The precondition is the intellectual acceptance by the villagers, the guaranteeing mechanism is the dynamic improvement of the various systems, and the external condition is the support of higher authorities, From the perspective of constructing the cooperative system, the previous factors are essential. From the perspective of operational efficacy, the key factor is the potential improvement of economic benefits, which determines to what extent the cooperative will be supported by the herdsmen.

Intellectual acceptance by the herdsmen

According to the herdsmen and other experts who have studied in Meilong previously, prior to the establishment of Meilong Cooperative, the village had already explored a more mature manner of cooperative operation, such as pricing the factors of production, zoning and rotating grazing, stock allocation of members' livestock assets, reducing livestock, distributing self-feeding sheep, the system for checking and counting livestock, and the stock system. However, with the limited knowledge of the herdsmen, they did not possess the concept of share-holding cooperatives, so they could not use that label to define the operations of Meilong

\footnotetext{
${ }^{7}$ See Qinghai Commissioner's Office: Village-based Task Force Leads Poor Village Cadres to Learn "Meilong Model".
} 


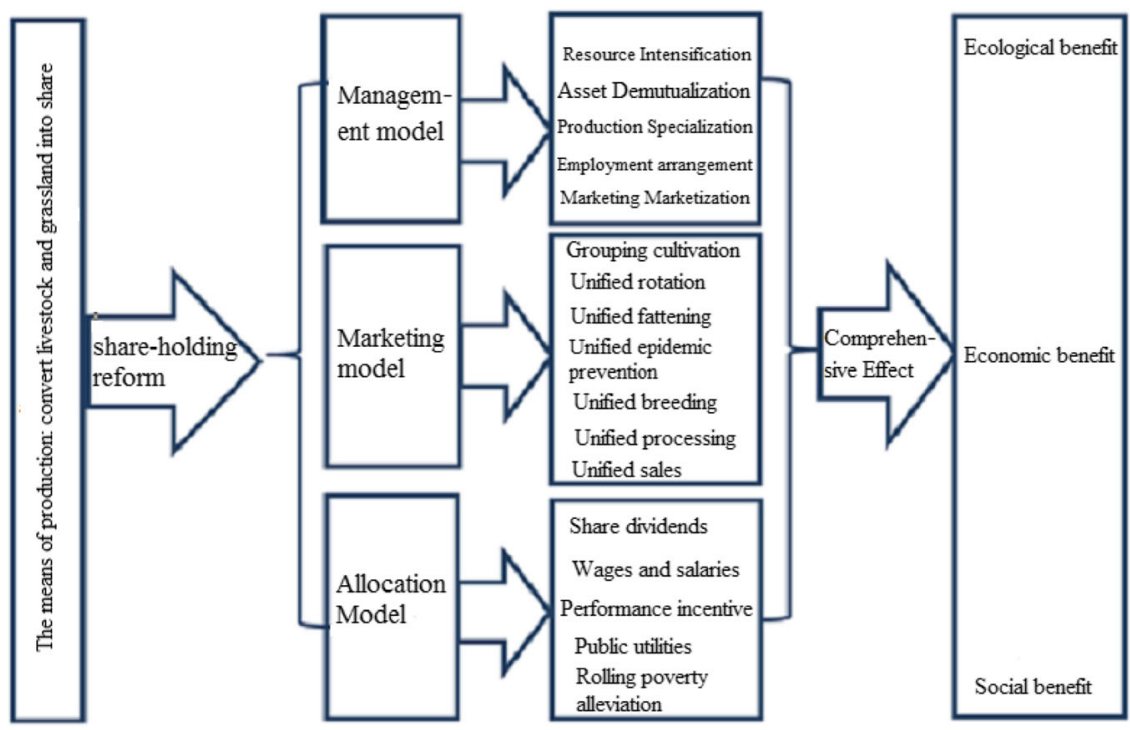

Fig. 5 Model Analysis and Theoretical Effect of Meilong Share-holding Cooperatives. Source: Based on the first-hand data obtained by Meilong Cooperative Research Institute

Village. In 2008, the whole province launched a poverty alleviation campaign in the villages. At that time, seven villages were selected as pilot projects, and a team of experts was formed to study how poor pastoral villages develop. In light of the existing cooperative structure in Meilong village (see Fig. 6), the experts proposed to formally establish the "Meilong ecological animal husbandry share-holding cooperative" and formulated a general procedure of giving out the shares. In essence, the cooperative

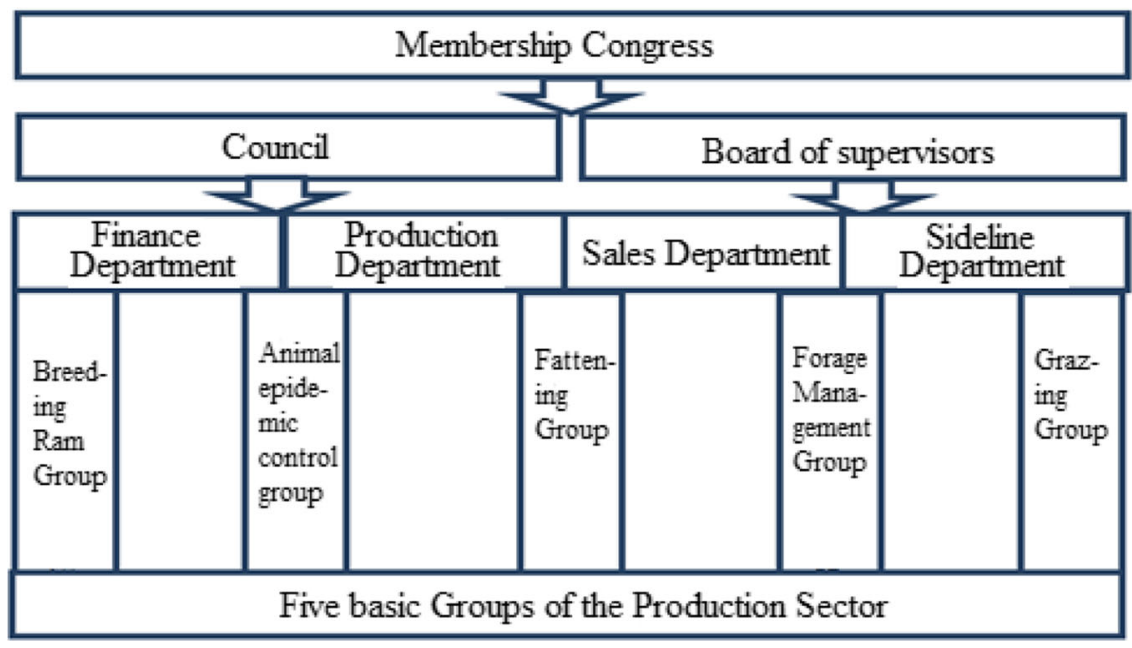

Fig. 6 Organization chart of Meilong Cooperative. Source: Research and interview in Meilong Village 
concept created by the villagers is still being applied. In this case, the villagers' acceptance of the ecological animal husbandry cooperative will bear fruit for years to come.

However, not all pastoral villages are like Meilong. For example, more than 50 other "cooperatives" such as Qikazhe, Yangxu, Seltang, Rijia Lingbu, Jigang, and Qulong are not well accepted by the villagers there because of a lack of early cultivation of the of concepts cooperative management. Most of them are unwilling to give their pastures and cattle and sheep to the cooperatives for unified management. Herdsmen with good grassland conditions think that the output of unified management is inferior to what they can achieve by themselves. Poor herdsmen think that they need to be able to sell cattle and sheep at any time to subsidize their households, while waiting for a dividend or bonus at the end of the year from the cooperative causes an inconvenience in their lives. As a result, these cooperatives only exist as empty shells, without any stockholders of the means of production. A cooperative model that is based on the existing concepts and local self-creation is more acceptable to herdsmen than as a foreign concept, and the cooperative model is more suitable for the implementation of the development of new pasturelands in the existing cooperatives.

\section{Organization structure and system design}

Since its establishment, the Meilong Cooperative established and elected a threelevel organization. The congress, made up of members, have the highest decisionmaking power. The chairmen, supervisors and members of the various councils and supervisory boards are elected democratically by these congresses. Together with the congresses, they constitute the highest decision-making and management supervisory body of cooperatives.

Based on the management needs and responsibilities for the production and operations of cooperatives, four middle-level management and service organizations have been set up, including a Finance Department, a Production Department, a Sales Department and a Multi-Economic Department. In addition, based on the production needs, the production part is divided into five grass-roots groups, with a breeding ram management group, a fattening group, a grazing group, a forage management group, and an animal epidemic prevention and control group.

The important matters of the cooperatives are decided through the deliberations of the congresses. In order to pursue democratic management, the Meilong Cooperative implemented the system of "four meetings and two publications" of "Council proposals, Supervisory board and Council deliberations, Party branch deliberations, Congressional resolutions, as well as openness about financial and social affairs", improved thes distribution of surplus from the cooperatives, and guaranteed democratic rights of the members to know and decide.

\section{Democratic supervision system}

The Meilong Cooperative also implements an open system related to social affairs, finance and internal distribution, which is conducive to democratic management and supervision by the whole membership. 
The matters that are discloses are the major business decisions and implementations of the cooperative, the financial revenue and expenditures, the distribution of surplus, the balance sheet, the profit statement, the profit distribution statement and notes about the statement audited by the board of supervisors. In its financial management, the Meilong Cooperative has formulated the principle of "private and civil management for the benefit of the people", which includes the management of the funds for the shares of each member and the management of cooperative funds. Enterprises wholly owned by cooperatives or jointly established with external groups shall be accounted for independently.

\section{A strengthened learning and training system}

Recognizing the limitations created by the low education level in the cooperatives, the Meilong Cooperative has formulated a learning system, which determines the educational content according to the needs of production, operation and service. Attendance is kept in meetings and studies, and money will be deducted for unexcused absences. The research group consulted the minutes of Meilong Cooperative from 2008 to 2018, and found that some rules and regulations can be implemented in practice, which was further confirmed in the interviews with cadres and herdsmen. An adaptive system to construct, maintain, and implement policies is the key factor for the survival and effectiveness of the Meilong Cooperative.

Governmental funding and policy support

In 2008, Tianjun County created a number of preferential policies to vigorously support the construction of new pasture lands. At the same time, in accordance with the "Tianjun County Animal Husbandry Reward and Compensation Measures", in 2017, livestock hardship allowances and subsidies for the purchase of agricultural machinery were granted to herdsmen in the county, and 3419 households in the county were equipped with tents, television, stoves, solar power, and other equipment. In addition to this county-level support, support on the provincial, state, and national levels was also a powerful driving factor. From the beginning of the Meilong Cooperative's founding to the present time, the subsidies and rewards received there are the highest in all cooperatives. The strong support of the government is an important guarantee for the effectiveness of Meilong Cooperative.

\section{Conclusions and suggestions}

How can cooperatives achieve sustainable development? The 10-year history of the Meilong Cooperative has shown that the accumulation and cultivation of cooperative ideas are the basic preconditions before the system can be constructed, while the completeness of organization, the design of internal systems, and the ongoing, active improvement of supervisory system are decisive factors, and the financial and policy support of the government is the important guarantee. All these factors are indispensable. The universality and popular value of the Meilong Model are 
conditional upon the comprehensive endowment of pastoral areas, the degree of recognition and acceptance among the herdsmen, the completeness of the organization, the active, local improvement of the system design and supervisory system. Using the Meilong model as a reference, the actual situation of different pastoral areas must be combined with scenario analysis and prediction in order to determine whether the model should be promoted in a particular region. Each pastoral area should establish its own model of operations and development according to its own situation and the specific demands of its herdsmen. From the government's point of view, it is necessary to guide the development of cooperatives with a more comprehensive system that uses scientifically indexed data, which should fully reflect the overall benefits to the ecology, economy and society. The local conditions must be met with targeted support, and the design of the system must be according to the different situations of each pastoral area. The policy support given to the different cooperatives must be made complete clear. The government should achieve this targeted support by supporting this developmental direction, encouraging a diversified business model, and promoting the formation of a complete industrial chain.

Meilong has experienced various challenges through the10 years of its development. It established good models in animal husbandry development and the construction of related systems, and achieved comprehensive ecological, economic and social improvements. The greatest contribution of Meilong model is that it highlights a livestock cooperative where herdsmen jointly seek development through collective equity. This cooperation model is worthy of affirmation, but, in the process of its operation, the concept of success has been enlarged. Therefore, in order to draw lessons from or promote the experience of Meilong Model, several issues must be examined.

Cooperatives are a current trend in development, but they need to be regulated according to local conditions. Through the present investigation and analysis, the cooperative model is the theoretical trend of development, but, in view of the actual situation of each pastoral area, village and township as well as the herdsmen's educational level, the Meilong model cannot be promoted as a universal standard for every pastoral area, but the development in each other should be based on its situation and the requirements of the local herdsmen. Based on different situation of each pastoral area, such an approach is designed to avoid the phenomenon of wild, false cooperation.

The sustainable development of cooperatives is conditional. The precondition is the accumulation of villagers and the cultivation of advanced ideas among them. The needed guarantee is the ongoing, active improvement of both the internal operations and supervision. The external condition that aids in development is the support of higher authorities. From the perspective of constructing a system, the above factors are indispensable. From the perspective of operational effectiveness, the key factor is the actual improvement in economic benefits, which determines to what extent the cooperative will be supported by the herdsmen.

The cooperative as a society can act as a double-edged sword. The impact of an increased scale could promote the sharing and overlapping of resources among the cooperatives; however, this would require increased standardization of the different 
management tasks in order to protect the vital interests of herdsmen from being lost among the crowds. There is a need to strengthen the education and training of herdsmen to enhance their quality and spirit of ownership.

The government's financial support for cooperatives should be accurately accounted for. Government support for cooperatives should accurately judge the different ways to support different cooperatives according to their resources, encourage cooperatives to form a complete industrial chain, encourage diversified business models, achieve targeted support that avoids waste, and must be cautious about "one size fits all" thinking.

A further step will involve the implementation of education and technical training for the herdsmen, cultivating new business entities, and solving the unemployment problem of surplus labor force. In the questionnaire interviews with herdsmen, $100 \%$ of the respondents were worried about the unemployment rate. They generally believe that the professional division of labor within cooperatives can only provide jobs for a small number of the unemployed, while most of the surplus labor forces idle due to lack of other skills. The herdsmen that were interviewed believed that they were sui for industries related to animal husbandry, and their appeal was "to form cooperatives that create an industrial chain with animal husbandry as the leading industry". In this regard, local governments should intervene to cultivate new herdsmen that meet the needs of the development of modern ecological animal husbandry, support new managers to execute the communal animal husbandry services, and encourage college graduates, college students, village officials and agricultural technicians to establish professional cooperatives for herdsmen.

Emphasis should be placed on the establishment of brands for each cooperative. In the process of improving the operations of the share-holding cooperatives, these cooperatives should strive to improve their industrial infrastructure, improve the quality of their products, cultivate new areas of economic growth, and create cooperative brands. This can be accomplished by means such as the vigorous promotion of organic pasturelands and branding, actively building an integrated development plan for multiple industries, and strengthening the collective assets of cooperatives, which will therefore to enhance their own development capacity and ability to be industrial leaders.

Acknowledgements Not applicable.

\section{Authors' contributions}

HY conducts the whole investigation and designs the framework. YG and WJ are responsible for the data collection, data cleaning and calculation. Five authors discussed together for the contents and wrote the whole manuscripts together. All authors read and approved the final manuscript.

\section{Funding}

Not applicable. 


\section{Availability of data and materials}

Available from the author upon request.

\section{Ethics approval and consent to participate}

Not applicable.

\section{Consent for publication}

Not applicable.

\section{Competing interests}

The authors declare that they have no competing interests.

\section{References}

Fu, Chen. 2006. Rural Cooperative Economy in China: Organizational Forms and Institutional Changes, 136. Beijing: China Economic Press.

Li, Shuangyuan. 2011. Situation, Evaluation and policy Ideas of Development Mode of Grassland Ecological Animal Husbandry. Chinese Journal of Agricultural Resources and Regional Planning 32 (2): 38-43.

Liang, Weihua. 2016. Study on development strategy of the professional cooperatives of herdsmen in Xinyuan town, a master thesis of Lanzhou University.

Liu, Wenhua. 2012. Editor-in-chief: Economic law. 4th ed, 142-143. Beijing: Renmin University Press.

Min, Xiaohua. 2018. An Analysis on the infactors of Ecological Livestock Husbandry. Business and Management 2: 52-53.

Yu, Jiwe. 2011. An Introduction to Share-holding Economics. 6th ed, 36. Shanghai: Fudan University Press.

Zhang, Min. 2018. The Total Factor Operation Mode under the Collaborative Governance Framework, North Economy. Vol. 9, 60-63.

\section{Publisher's Note}

Springer Nature remains neutral with regard to jurisdictional claims in published maps and institutional affiliations. 